\title{
Erratum to: Establishment of an Intraoperative Staging System (iStage) by Improving UICC TNM Classification System for Papillary Thyroid Carcinoma
}

\author{
Yasuhiro Ito · Kiyoshi Ichihara - Hiroo Masuoka • Mitsuhiro Fukushima • \\ Hiroyuki Inoue $\cdot$ Minoru Kihara Chisato Tomoda - Takuya Higashiyama • \\ Yuuki Takamura $\cdot$ Kaoru Kobayashi $\cdot$ Akihiro Miya $\cdot$ Akira Miyauchi
}

Published online: 20 November 2010

(C) Société Internationale de Chirurgie 2010

Erratum to: World J Surg (2010) 34(11):2570-2580

DOI 10.1007/s00268-010-0710-2

Figure $7 \mathrm{~b}$ is incorrect in the original article. The correct figure is as follows:

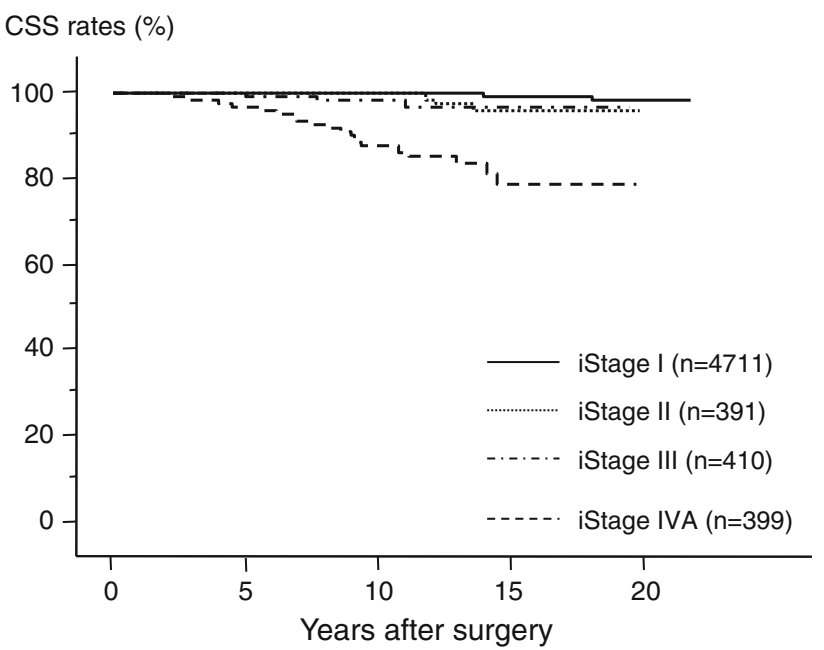

Fig. 7 b Comparison of CSS among patients with papillary carcinoma classified as iStage I-IVA
The online version of the original article can be found under doi:10.1007/s00268-010-0710-2.

Y. Ito $(\bowtie) \cdot$ H. Masuoka $\cdot$ M. Fukushima $\cdot$ H. Inoue

M. Kihara · C. Tomoda · T. Higashiyama · Y. Takamura ·

K. Kobayashi - A. Miya - A. Miyauchi

Department of Surgery, Kuma Hospital, 8-2-35,

Shimoyamate-Dori, Chuo-ku, Kobe City 650-0011, Japan

e-mail: ito01@kuma-h.or.jp

\section{K. Ichihara}

Department of Clinical Laboratory Sciences, Faculty of Health

Sciences, Yamaguchi University School of Medicine,

Minami-Kogushi 1-1-1, Ube City, Japan 